\title{
WAVE RUNUP ON DIKES AND BEACHES
}

\author{
Jill Pietropaolo ${ }^{1}$, Nobuhisa Kobayashi ${ }^{2}$, and Jeffry A. Melby ${ }^{3}$
}

\begin{abstract}
In the United States, the Federal Emergency Management Agency (FEMA) is in the process of updating its coastal flood risk maps in order to determine which locations are threatened by storm surge and wave action. These maps require the prediction of extreme wave runup. A method for predicting the runup height along the entire coast must be robust, reliable, and applicable to many different coastal features. Kobayashi et al. (2008) developed a time-average probabilistic model that predicts wave runup statistics instead of the time series of shoreline elevation. This numerical cross-shore model, CSHORE, is extended to the wet-dry zone above the still water level to predict irregular wave runup on impermeable dikes and gentle impermeable slopes. To show the CSHORE's capability in predicting runup on beaches with different geometries, the computed results from the model are compared to measured data from a variety of experiments. CSHORE is tested against 40 wave runup tests on an impermeable dike on a barred beach, 97 wave runup tests on an impermeable dike with a gently sloping beach, and 120 tests for wave runup on gentle uniform slopes. The measured $2 \%$ and $1 \%$ exceedence runup heights are predicted within errors of about $20 \%$. The spectral significant wave height, $H_{m o}$, and a representative period are used for input to CSHORE.

The measured and computed cross-shore variations of $H_{m o}$ are also computed and compared to measured data to show the capabilities and limitations of CSHORE in regards to predicting to wave transformation. Both the spectral period, $T_{m-1,0}$, and the peak period $T_{p}$ at $x=0$ are adapted as representative periods used in CSHORE to assess the period effect in CSHORE. The tested CSHORE is ready for practical applications such as FEMA's coastal flood mapping, and is a good practical choice because it can be used to predict beach and dune profile changes.
\end{abstract}

Keywords: runup, CSHORE, wave transformation

\section{INTRODUCTION}

Wave runup, the upper elevation limit of wave action above the still water level is of particular importance in determining areas affected by wave action during extreme events. The U.S. Federal Emergency Management Agency (FEMA) uses wave runup elevation to create coastal flood risk maps in order to determine areas that are at risk of wave action during extreme events (Crowell et al 2010). Wave runup is also necessary to determine a crest height to which a coastal structure should be designed in order to prevent wave overtopping during extreme events. This is a major concern for structures whose primary function is sea defense such as dikes and levees (EurOtop Manuel 2007).

There are a number of ways that extreme wave runup, such as wave runup exceeded by $2 \%$ or $1 \%$ of incident irregular waves, can be predicted. There are several empirical formulas which have been utilized for predicting wave runup. These formulas are easy to use and computationally efficient, but they are often limited to specific data fitted to the formulas, and are not always applicable to different beach bathymetries (Kobayashi et al. 2008). In addition, these runup formulas for coastal structures require the representative wave height and period at the toe. These can be difficult to specify, especially if the toe is located in the surf zone. Wave transformation from an offshore point to the swash zone is neglected even though wave setup and swash on a beach depends on bathymetry of the entire surf zone (e.g. Raugenhimer et al. 2001).

An alternative method is the use of time-dependant models that predict the time series of the hydrodynamic variables on specific bathymetries. Time-dependent models based off of nonlinear shallow-water wave equations (e.g. Raugehhimer and Guza 1996 and Raubinhimer 2002) or Boussinesq wave equations (e.g. Nwogu and Demirbilek 2010) may also be used to predict wind waves and infragravity wave motions in detail, but they require significant computational time and are not easy to use for coastal flood risk mapping which requires numerous computations. In addition, mapping typically only requires the landward extent of flooding. The excess details produced by these models are often not necessary. The computational time and difficulty of use causes these models to be inefficient for practical use (Kobayashi et al. 2008).

For a practical application such as coastal flood mapping over the entire United States, a model that is robust and computationally efficient is necessary. Kobayashi et al. (2008) developed a time-averaged probabilistic model to predict irregular wave runup statistics instead of the time series of the shoreline elevation. The model, CSHORE, was initially limited to the wet zone only, but was extended to the wet and dry zone above the still water shoreline by Kobayashi et al. (2010). CSHORE is a cross-shore model which is computationally efficient and convenient for practical applications. CSHORE allows for an arbitrary bottom profile and can predict beach profile evolution if necessary (Kobayashi et al. 2010). In the following, CSHORE is tested against a variety of different conditions at different beaches to show the model's applicability for use in predicting irregular wave runup on dikes

\footnotetext{
${ }_{1}^{1}$ Masters student, Center for Applied Coastal Research, University of Delaware, Newark, DE 19716

${ }^{2}$ Professor, Center of Applied Coastal Research, University of Delaware, Newark, DE 19716

${ }^{3}$ U.S. Army Corps of Engineers Research and Development Center, Vicksburge, MS 39180
} 
with barred and sloping beaches and beaches with gentle slopes. In addition, the model is compared to the cross shore variation of the spectral significant wave height, $H_{m o}$, to show its capabilities and limitations in predicting wave transformation.

\section{NUMERICAL MODEL CSHORE}

CSHORE is a cross-shore numerical model which is locally alongshore uniform. The model is composed of two parts, a wet zone where water is always present and a wet dry zone in the swash area. In the wet zone CSHORE uses the time averaged continuity, momentum and energy equations to predict the mean free surface elevation, significant wave height and mean velocity. The cross-shore coordinate, $x$ is positive onshore. The seaward boundary is located at $x=0$, and is where incident waves are specified. The seaward boundary is assumed to be out of the surf zone such that wave setup can be assumed to be 0 . Incident irregular waves are assumed to propagate in the $x$ direction. Significant wave height and a representative period are specified at the seaward boundary. CSHORE predicts the significant wave height transformation from the input wave height at the seaward boundary to the wave height at the toe of the dike. This is necessary to improve runup computation in comparison to empirical formulas based on wave conditions at the dike toe. Spectral significant wave height $H_{m o}$ is taken as four times the standard deviation of the free surface $\sigma_{\eta}$ and is given as $H_{m o}=4 \sigma_{\eta}$.

\section{Governing equations of wave runup}

Wave runup is predicted using a modification of the method employed by Kobayashi et al. (2008) who analyzed wave runup on permeable slopes in the wet zone only. Their method is based on runup measurements taken on a runup wire placed vertical height $\delta_{r}$ above the bottom elevation, denoted as $z_{b}$. The runup wire determined the instantaneous elevation $\eta_{r}$ of the free surface above the SWL by measuring where the free surface intersects with the wire. The mean elevation $\overline{\eta_{r}}$ and standard deviation $\sigma_{r}$ of the time-varying $\eta_{r}$ are estimated using the three intersection points $\left(x_{1}, z_{1}\right),\left(x_{2}, z_{2}\right)$, and $\left(x_{3}, z_{3}\right)$ along the wire as seen in Figure 1. These intersection points along the wire are found using the bottom elevation, wet probability $\left(P_{w}\right)$, average depth $(\bar{h})$, and wave height $\left(H_{m o}\right.$ $\left.=4 \sigma_{\eta}\right)$. The mean water level during the entire duration of the runup measurement is given by $\left(z_{b}+P_{w} \bar{h}\right)$. The water levels corresponding to one standard deviation $\left(P_{w} \sigma_{\eta}\right)$ above and below the mean water level are given by $\left(z_{b}+\right.$ $\left.P_{w}\left(\bar{h}+\sigma_{\eta}\right)\right)$ and $\left(z_{b}+P_{w}\left(\bar{h}-\sigma_{\eta}\right)\right)$, respectively. These three water levels are used to obtain the three intersections.

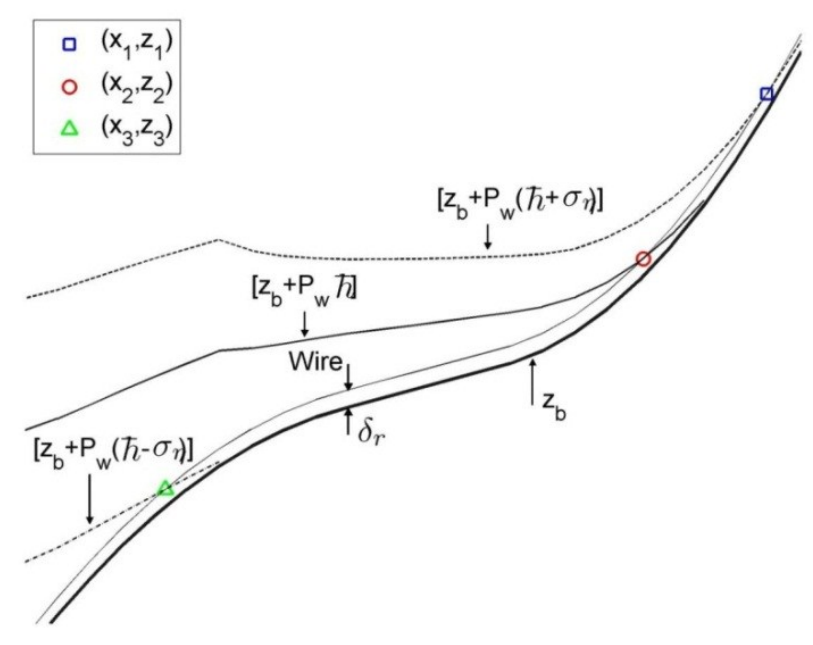

Figure 1: Intersection points along runup wire placed at height $\delta_{r}$ above the impermeable bottom 
The mean water level $\overline{\eta_{r}}$ above SWL and standard deviation $\sigma_{r}$ are estimated as

$$
\overline{\eta_{r}}=\frac{z_{1}+z_{2}+z_{3}}{3} ; \sigma_{r}=\frac{z_{1}-z_{3}}{2} ; S_{r}=\frac{z_{1}-z_{3}}{x_{1}-x_{3}}
$$

where $S_{r}=$ representative slope in the zone of the runup measurement.

The crest elevation of the time-varying elevation $\eta_{r}$ is defined as the runup height $R$ above SWL. The exceedence probability $P$ for the runup height above the mean water level, $(R-\bar{\eta})$ is assumed to be given by the Rayleigh distribution (Kobayashi et al. 2008)

$$
P=\exp \left[-2\left(\frac{R-\overline{\eta_{r}}}{R_{1 / 3}-\overline{\eta_{r}}}\right)^{2}\right]
$$

where $R_{1 / 3}=$ significant runup height defined as the average of $1 / 3$ highest values of $R$. The significant runup height is estimated as

$$
R_{1 / 3}=\left(1+4 S_{r}\right)\left(\overline{\eta_{r}}+2 \sigma_{r}\right)
$$

If the probability distribution of $\eta_{r}$ is Gaussian, $R_{1 / 3}=\left(\overline{\eta_{r}}+2 \sigma_{r}\right)$. The correction term $\left(4 S_{r}\right)$ in Eq. (3) is obtained on the basis of the subsequent comparisons of the numerical model with the data by van Gent (1999a,b). The runup heights $R_{2} \%$ and $R_{1 \%}$ corresponding to $P=0.02$ and 0.01 , respectively, in Eq. (2) are given by

$$
R_{2 \%}=\overline{\eta_{r}}+1.40\left(R_{1 / 3}-\overline{\eta_{r}}\right) ; R_{1 \%}=\overline{\eta_{r}}+1.52\left(R_{1 / 3}-\overline{\eta_{r}}\right)
$$

\section{Input parameters}

CSHORE contains two empirical parameters that are input and used to calibrate the model. The first is the breaker ratio parameter $\gamma$. This is taken as its default value of $\gamma=0.7$ in the following computations. The break ratio parameter affects the cross-shore variation of the spectral significant wave height $H_{m o}=4 \sigma_{\eta}$. CSHORE does not separate wind and infragravity waves. When $\gamma$ was increased to 0.8 , the computed $H_{m o}$ is found to increase by about $10 \%$. The computed runup is also found to increase about $10 \%$ when $\gamma$ is changed from 0.7 to 0.8 .

The other empirical parameter used to calibrate the model is the bottom friction factor $f_{b}$. Typical field observations of wave runup on natural beaches by Raubenhimer et al. (2004) showed $f_{b}=0.01-0.06$. Wave runup was calculated using $f_{b}=0.01$ and $f_{b}=0.05$ to test the model's sensitivity to bottom friction. CSHORE was found to be insensitive in this range of $f_{b}$. The $500 \%$ change in $f_{b}$ caused less than $20 \%$ variation in $R_{2} \%$ and $R_{1 \%}$. The computed $H_{m o}$ is also found to be insensitive to changes in $f_{b}$. For the following computation using van Gent's 1999 data, use is made of $f_{b}=0.02$. The value of 0.02 is now the default value for $f_{b}$ for impermeable smooth slopes with sandy beaches.

\section{WAVE RUNUP ON DIKES AND BARRED BEACHES}

The numerical model CSHORE is applied to data from a physical model based on Froud similitude in a wave flume that stimulated field measurements by van Gent (2001). The field measurements of wave runup were made on dike of the Petten Sea defense in the Netherlands (van Gent 2001). The physical model based on Froude similitude with a length scale of $1 / 40$ and a time scale of $\sqrt{40}$ was constructed in wave flume to simulate field measurements. This physical model reproduced field data with difference less than $10 \%$, which more accurate than numerical models. The computed significant wave height $H_{m o}$ and extreme runup $R_{2 \%}$ and $R_{1 \%}$ using the numerical model CSHORE are compared to the measured data from the physical model. The following comparison makes use of the physical model data tabulated by van Gent (1999a) who presented the data in the prototype length and time scales.

The test series for the Pattern Sea defense is called series P. The experimental setup for the prototype scale can be seen in Figure 2. The seaward boundary, located at $x=0$, was taken at a gage located immediately outside the surf zone so that wave setup can be assumed to be 0 at $x=0$. Throughout the 40 tests in series $\mathrm{P}$, the still water level (S) ranged from $z=0$ at the lowest SWL to $4.3 \mathrm{~m}$ at the highest. The bar is located at $x \approx 160 \mathrm{~m}$ and $z=-4.8 \mathrm{~m}$. This is shallow enough for wave breaking to occur for a large $H_{m o}$. The seaward slope of the bar is $1 / 30$, while the 
landward slope is $1 / 25$. The dike consists of the slopes of $1 / 4.5,1 / 20$, and $1 / 3$. The toe of the dike is located at $x=$ $570 \mathrm{~m}$ and $z=-1.9 \mathrm{~m}$. This bottom geometry was specified as input to CSHORE.

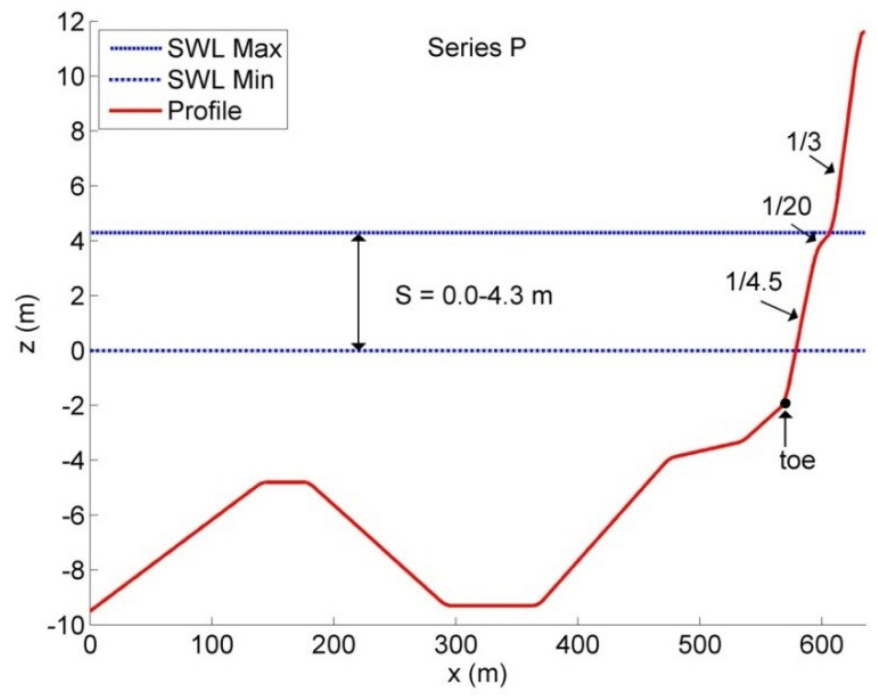

Figure 2: Experimental setup for series $\mathbf{P}$

\section{Wave conditions}

The values of still water level, spectral significant wave height, spectral period, and peak period tabulated by van Gent (1999a) for each of the 40 tests in series $P$ and are used as input or to determine input into the numerical model CSHORE. The ranges for all of these conditions are show in Table 1.

Table 1: Wave Conditions at $\mathrm{x}=0$ for Series $\mathrm{P}$.

\begin{tabular}{|c|c|c|c|c|c|}
\hline Series & $\begin{array}{c}\text { Number of } \\
\text { Tests }\end{array}$ & $\begin{array}{c}\boldsymbol{T}_{\boldsymbol{m}-\mathbf{1}, \boldsymbol{0}} \\
(\mathbf{s})\end{array}$ & $\begin{array}{c}\boldsymbol{T}_{\boldsymbol{p}} \\
(\mathbf{s})\end{array}$ & $\begin{array}{c}\boldsymbol{H}_{\boldsymbol{m} \boldsymbol{o}} \\
(\mathbf{c m})\end{array}$ & $\mathbf{K}_{\mathbf{R}}$ \\
\hline $\mathrm{P}$ & 40 & $6.9-15.3$ & $7.2-18.5$ & $180-600$ & $0.26-0.37$ \\
\hline
\end{tabular}

The spectral period ranged from $6.9 \mathrm{~s}$ to $15.3 \mathrm{~s}$ while the peak period ranged from $7.2 \mathrm{~s}$ to $18.5 \mathrm{~s}$. The significant wave height ranged from $180-600 \mathrm{~cm}$.

The spectral wave period $T_{m-1,0}$ is defined as

$$
T_{m-1,0}=\frac{m_{-1}}{m_{0}} ; m_{n}=\int_{0}^{\infty} f^{n} S(f) d f \quad(n=0 \text { and }-1)
$$

where $S(f)$ = wave energy spectrum as a function of frequency $f$. The spectral period is now used in Europe (e.g., EurOtop Manual 2007) as a representative wave period instead of the spectral peak period $T_{p}$ which is difficult to specify for multipeaked spectra. Both $T_{m-1,0}$ and $T_{p}$ are implemented as the representative period used in CSHORE to assess the period effect of CSHORE.

CSHORE makes the assumption that period is constant in the computation domain of $x>0$. Figure 3 shows the ratios of peak period and the spectral period at $\mathrm{x}=0$ as well as the ratios of both periods at the toe of the dike and at $\mathrm{x}=0$ for the 40 tests in series $\mathrm{P}$. The ratio of $T_{p}$ to $T_{m-1,0}$ at $\mathrm{x}=0$ ranged from 0.98 to 1.41 . For the JONSWAP spectrum, $T_{m-1,0}=T_{p} / 1.1$ (van Gent 1999a). The ratio between $T_{m-1,0}$ at the toe and $x=0$ ranged between of $0.86-1.39$. This ratio for $T_{p}$ was in the range of $0.88-2.32$, indicating that $T_{p}$ varied more from $x=0$ to the toe. CSHORE makes the assumption that wave period remains constant between $x=0$ and the toe. Based on these 
ratios, the assumption of constant wave period in CSHORE is more applicable to the spectral period $T_{m-1,0}$. This indicates that the spectral period is more representative of CSHORE's assumption of a constant period in the computation domain. It is because of this that $T_{m-1,0}$ is the recommended period in this study.

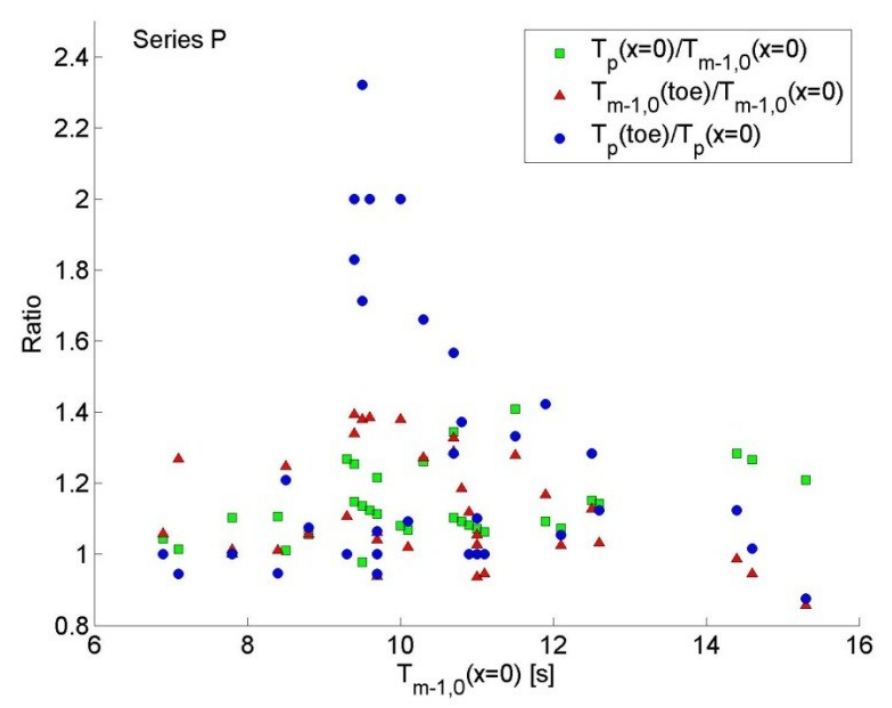

Figure 3: Wave period ratios as a function of $T_{m-1,0}$ at $x=0$ for series $P$

The spectral significant wave height is related to the root mean square wave height $H_{r m s}=\sqrt{8} \sigma_{\eta}$ which is used as input to CSHORE. In order to measure incident and reflected waves, three wave gages were used at $x=0$, 160,335 , and $505 \mathrm{~m}$. It is noted that incident waves at the toe $(\mathrm{x}=570 \mathrm{~m})$ were measured without the dike. $H_{m o}$ was large enough to allow breaking to occur during tests with a low still water level. The value of $H_{m o}$ listed in Table 1 does not include reflected waves. The value of $H_{m o}$ including the reflective waves at $x=0$ may be estimated as $H_{m o}$ $=\left(1+K_{R}^{2}\right)^{0.5}$. This is because partial standing waves decay seaward from the dike (e.g., Klopman and van der Meer 1999). $H_{m o}$ may increase by $3-7 \%$ in Table 1 if reflected waves with $K_{R}=0.26-0.37$ are included. This estimate is useful in estimating the error of CSHORE which does not account for reflected waves.

\section{Model comparison}

To show that CSHORE is capable of predicting wave transformation, the measured values of $H_{m o}$ at $x=0$, $160,335,505$, and 570 (toe) are compared to the model's computed value. Figure 4 shows a sample calculation for the $27^{\text {th }}$ test in series P. For this comparison, the SWL ( $\mathrm{S}$ in Fig. 2) is equal to $3.4 \mathrm{~m}, T_{m-1,0}=12.6 \mathrm{~s}, T_{p}=14.4 \mathrm{~s}$, and $H_{m o}=5.9 \mathrm{~m}$ at $x=0$. These parameters and the bottom geometry shown in Fig. 2 were used as input as the model. The first panel is the wave setup above the SWL. The berm of the 1/20 slope is submerged below the mean water level. The middle panel is the wet probability, $P_{w}$. The wet probability is one throughout the wet zone and decreases once the bottom, $z_{b}$, reaches the SWL. The bottom panel is the computed verses measured $H_{m o}$ for both $T_{m-1,0}$ and $T_{p}$. The spectral significant wave height for $T_{p}$ is slightly larger than that for $T_{m-1,0}$. There is fairly good agreement with both periods with the exception of at the toe. This increase in error at the toe is likely due to the fact that the measurements taken at the toe were without the dike, while the other measurements were done in the presence of the dike using three wave gauges to separate incident and reflected waves. The wave setup above the still water level and the wet probability are almost the same for $T_{m-1,0}$ and $T_{p}$.

In order to further show that CSHORE is capable of predicting the wave transformation from $x=0$ to the toe of the dike, the measured wave heights $H_{m o}$ at $x=0,160,335,505$, and 570 (toe) are plotted for all 40 tests in series P. The computed vs. measured spectral significant wave height is plotted for both the peak and spectral periods as shown in Figure 5. 


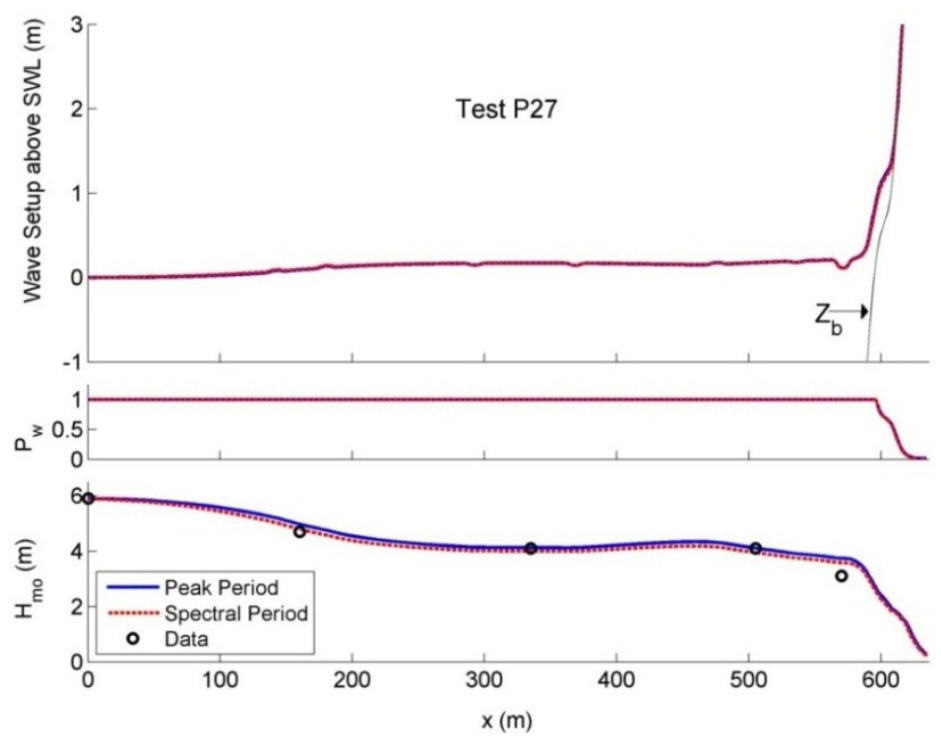

Figure 4: Sample calculation

The relative root-mean-error of the computed tests was calculated for each period using the equation (6),

$$
E=\left[\frac{1}{I} \sum_{i=1}^{I}\left(\frac{C_{i}}{M_{i}}-1\right)^{2}\right]^{0.5}
$$

where $E$ is the error, $I$ is the number of plotted points, and $C_{i}$ and $M_{i}$ are the measured and computed values of the ith point plotted in the figure. The agreement for both periods is similar, however it is slightly better for the spectral period. Figure 5 shows $T_{p}$ predicts slightly larger wave heights which lead to the slightly greater error than $T_{m-1,0}$. The toe is differentiated because the error, likely due to the measurement of wave height without the presence of the dike, was greater there. The computed $H_{m o}$ is predicted within $20 \%$ error with the exception of at the toe.

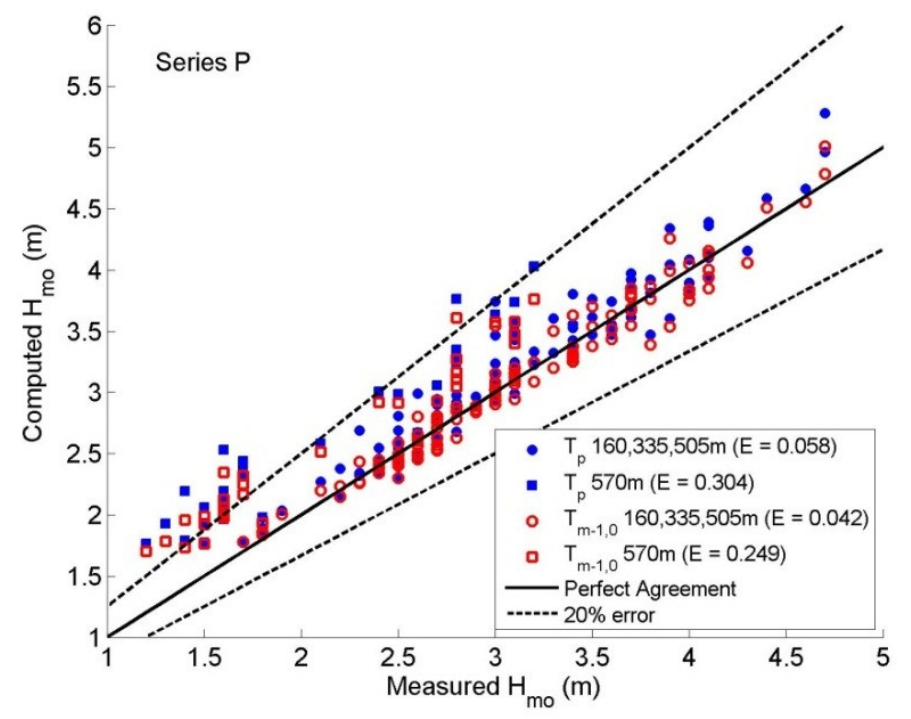

Figure 5: Computed vs. measured $\boldsymbol{H}_{m o}$ 
The measured wave runup on the dike was determined using a step gauge consisting of a beam with a large number of conductive probes. The probes were placed at a distance of $\delta_{r}=0.1 \mathrm{~m}$ (Fig. 1 - prototype scale) above the slope of $1 / 3$ in Fig.2. Figure 6 shows the measured and computed $R_{2 \%}$ and $R_{1 \%}$ above SWL, respectively, for the 40 tests in series P. The agreement for $R_{2 \%}$ and $R_{1 \%}$ is very similar because the measured $R_{2 \%}$ and $R_{1 \%}$ are well correlated and can be approximated by $R_{1 \%}=1.07 R_{2 \%}$ within $10 \%$ errors. The agreement is within $20 \%$ for most cases in series P. Like the wave height comparison, the agreement for both periods is similar and $T_{p}$ is predicted slightly larger runup heights than $T_{m-1,0}$.
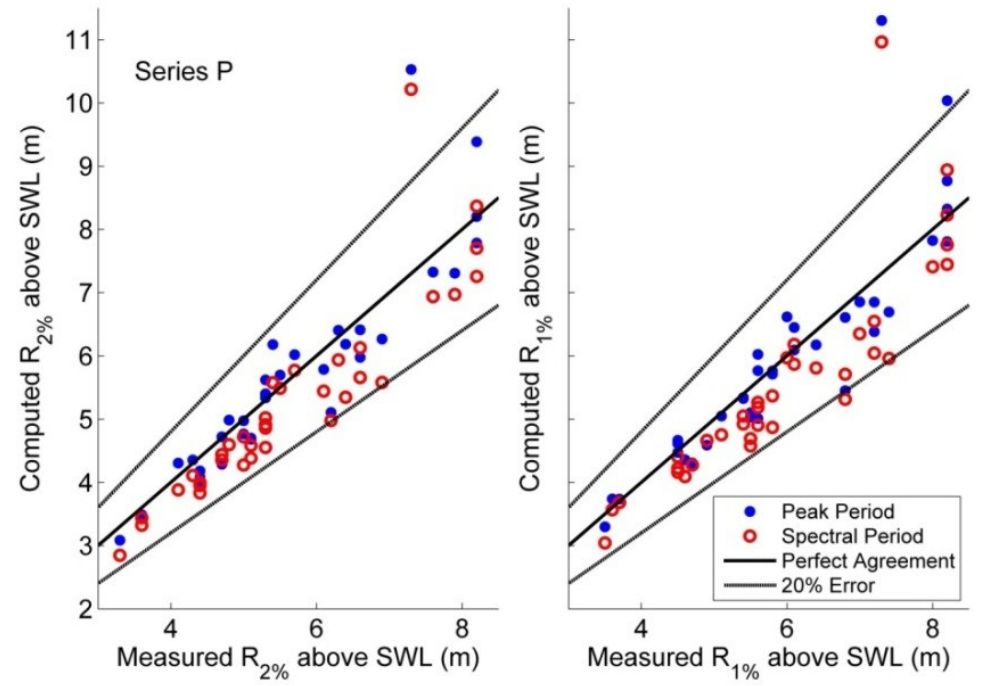

Figure 6: Computed vs. measured $\boldsymbol{R}_{2 \%}$ and $\boldsymbol{R}_{1 \%}$

\section{WAVE RUNUP ON DIKES WITH GENTLY SLOPING BEACHES}

Experiments on three physical models of dikes fronted by gently sloping beaches were also carried out van Gent (1999b). These tests included different setups of beach and dike slopes. There were 97 tests in all. The water level and wave conditions including double-peaked wave energy spectra were varied for the tests. The experimental procedure for these models was essentially the same as that for series P. Use is made of the data tabulated by van Gent (1999b). Like in series $P$, use is made of the length and time scales as of 40 and $\sqrt{40}$, respectively, between the prototype and model. The values of the still water level, significant wave height, spectral period, and peak period are used to make the three input files for CSHORE for the three test series. These tests are referred to as series A, B, and $C$. The three test series were conducted for the beach slopes of $1 / 100$ and $1 / 250$ and the dike slopes of $1 / 4$ and 1/2.5 as shown in Figure 7. The lowest still water level, $S$, of the experiments was set to 0 . The highest value of $S$ was $0.306 \mathrm{~m}$. The toe was located at $x=30 \mathrm{~m}$. The water depth at the toe was $4.7 \mathrm{~cm}$ below the lowest still water level. Wave breaking on the beach varied, increasing at lower S. The significant wave height used as input was measured at $x=0$. For all 97 tests, the location $x=0$ is mostly outside the surf zone, however when the still water level is very low this might not have been correct. Series A and B had a foreshore slope of $1 / 100$, while series $C$ had a foreshore slope of $1 / 250$. The slope of the dike was $1 / 4$ for series $A$ and $1 / 2.5$ for series $B$ and $C$.

\section{Wave conditions}

The values of still water level, spectral significant wave height, spectral period, and peak period tabulated by van Gent (1999b) for each of the 97 tests in series A, B, and C, and are used to make input files for the numerical model CSHORE. The number of tests and the ranges for all of the conditions at $x=0$ are show in Table 2. The conditions are similar to series $P$ if use is made of the length and time scales of 40 and $\sqrt{40}$, respectively, between the prototype and model. 


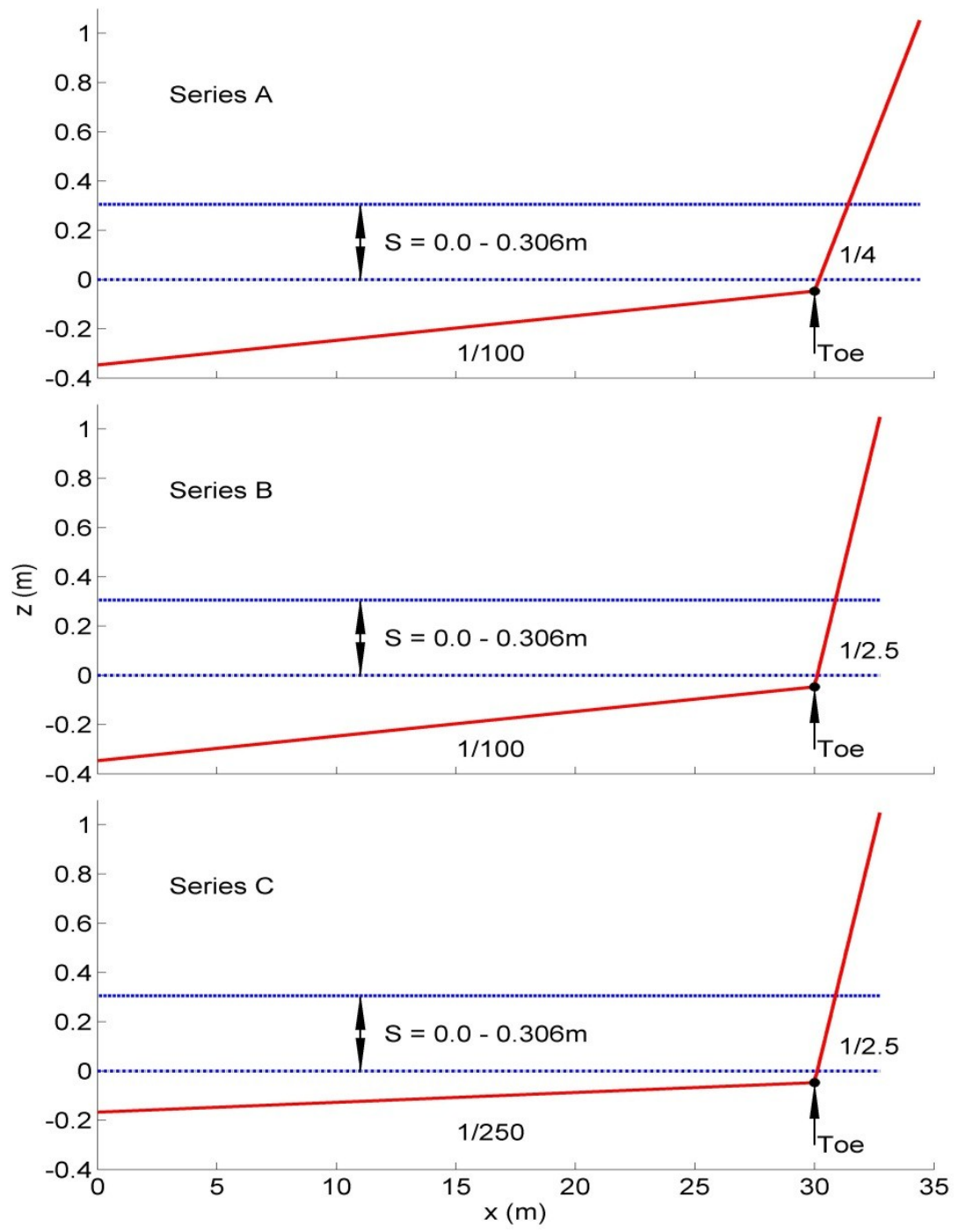

Figure 7: Experimental setup for series A, B, and C

Table 2 Wave Conditions at $x=0$ for Series A, B, and C

\begin{tabular}{|c|c|c|c|c|c|}
\hline Series & $\begin{array}{c}\text { Number of } \\
\text { Tests }\end{array}$ & $\begin{array}{c}\boldsymbol{T}_{\boldsymbol{m}-1, \boldsymbol{0}} \\
(\mathbf{s})\end{array}$ & $\begin{array}{c}\boldsymbol{T}_{\boldsymbol{p}} \\
(\mathbf{s})\end{array}$ & $\begin{array}{c}\boldsymbol{H}_{\boldsymbol{m o}} \\
(\mathbf{c m})\end{array}$ & $\mathbf{K}_{\mathbf{R}}$ \\
\hline $\mathrm{A}$ & 42 & $1.37-2.42$ & $1.28-2.48$ & $13.2-15.0$ & $0.21-0.36$ \\
$\mathrm{~B}$ & 31 & $1.38-2.30$ & $1.28-1.56$ & $13.2-15.0$ & $0.23-0.66$ \\
$\mathrm{C}$ & 24 & $1.40-2.68$ & $1.26-2.56$ & $7.9-15.4$ & $0.41-0.66$ \\
\hline
\end{tabular}


To test the validity of the CSHORE assumption that the period does not vary from $x=0$ to the toe, the ratios of wave periods at $x=0$ and the toe was calculated for both the $T_{m-1,0}$ and $T_{p}$ for series A, B, and C just as in series P. The ratio $T_{p} / T_{m-1,0}$ was also calculated. Fig. 8 shows these ratios of the wave periods at $x=0$ and the toe for the 97 tests in series A, B, and C.

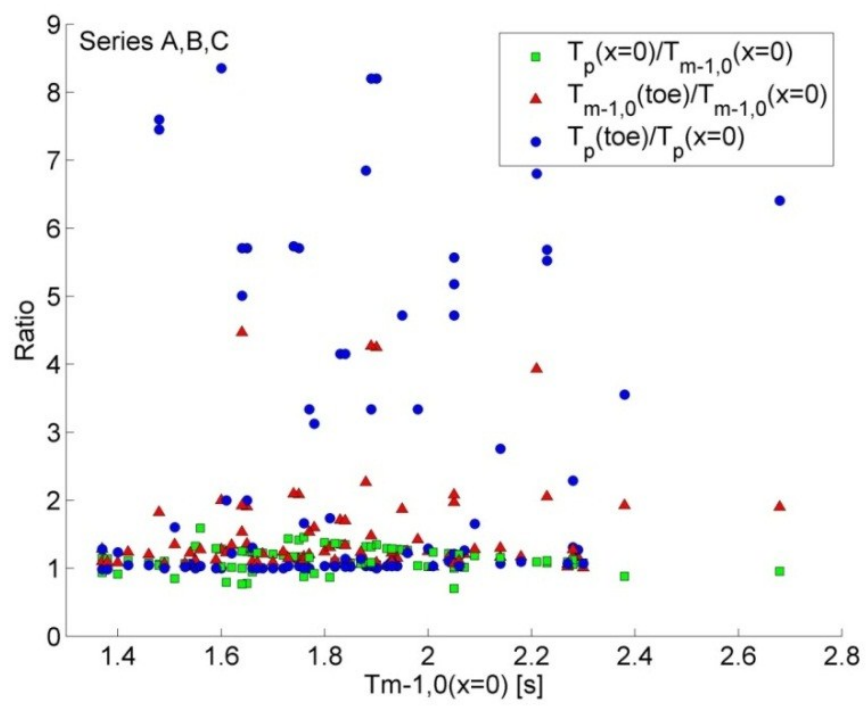

Figure 8: Wave period ratios as a function of $T_{m-1,0}$ at $x=0$ for series A, B, and C

The ratio $T_{p} / T_{m-1,0}$ at $x=0$ is in the range of $0.70-1.45$. The ratio between the measured periods at the toe and $x=$ 0 is in the range of $1.01-4.47$ for $T_{m-1,0}$ and $0.99-10.0$ for $T_{p}$. The wave periods $T_{m-1,0}$ and $T_{p}$ at $x=0$ (mostly outside the surf zone) are not very different. The wave periods can increase considerably from $x=0$ to the toe if wave breaking occurs on the gentle slope especially for double-peaked wave energy spectra. The cross-shore variability is less for $T_{m-1,0}$ than $T_{p}$, showing that $T_{m-1,0}$ is a more representative period for CSHORE.

\section{Model comparison}

CSHORE was used to compute $H_{m o}, R_{2 \%}$, and $R_{1 \%}$ for each test of series A, B, and C as it was done for series $\mathrm{P}$.

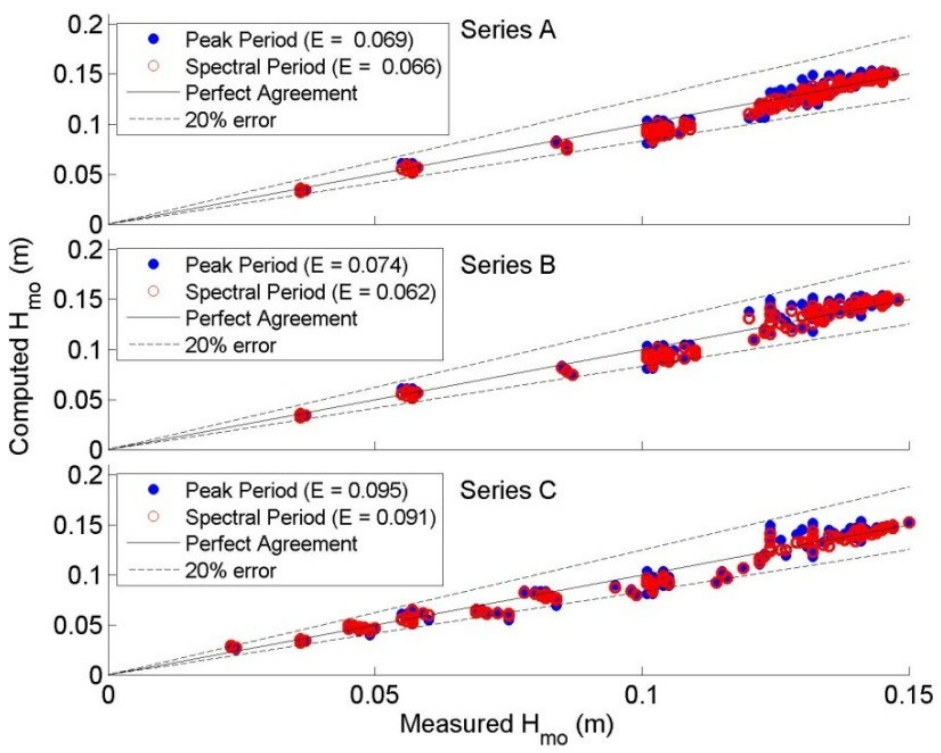

Figure 9: Computed vs. measured $\boldsymbol{H}_{m o}$ 
The measured $H_{m o}$ at $x=0$ was used as input to CSHORE. The wave transformation from $x=0$ to the landward limit of wave uprush on the dike was computed for each test. Like with series $\mathrm{P}$, both $T_{m-1,0}$ and $T_{p}$ were used as input for the representative period in CSHORE.

To show CSHORE's capability to predict wave transformation from $x=0$ to the toe of the dike with a gently sloping foreshore in front of it, the measured and computed $H_{m o}$ at $x=10,20$ and 30 (toe) $\mathrm{m}$ were compared for all 97 tests of series A, B, and C. Fig. 9 shows the comparison of the measured and computed $H_{m o}$ at $x=10,20$ and 30 (toe) $\mathrm{m}$ for series A, B, and C. Unlike what is seen in Fig. 5, which shows the comparison for series $\mathrm{P}$, the agreement remains similar at the toe for series $\mathrm{A}, \mathrm{B}$, and $\mathrm{C}$. The measured $H_{m o}$ at the toe is not distinguished from the rest of the measurements as in Fig. 9. The agreement is similar for the spectral and peak periods. The relative root-mean-square error was calculated for all three series including the toe using equation 6. Fig. 9 shows that CSHORE predicts the wave height transformation for all 97 tests within about $10 \%$ errors.

The measured wave runup on the dike was determined using a step gauge consisting of a beam with a large number of conductive probes. The height $\delta_{r}$ (see Fig. 1) of the step gauge was $\delta_{r}=2.5 \mathrm{~mm}$. All the 97 tests are plotted together because the agreement is similar for the three series. Figure 10 compares the measured and computed $R_{2 \%}$ and $R_{1 \%}$. Like with series $\mathrm{P}$, the computed value of wave runup for $T_{p}$ was higher than the computed value of $T_{m-1,0}$. CSHORE predicts $R_{2 \%}$ and $R_{1 \%}$ within errors of about $20 \%$ when $T_{m-1,0}$ at $x=0$ is used as the representative wave period.
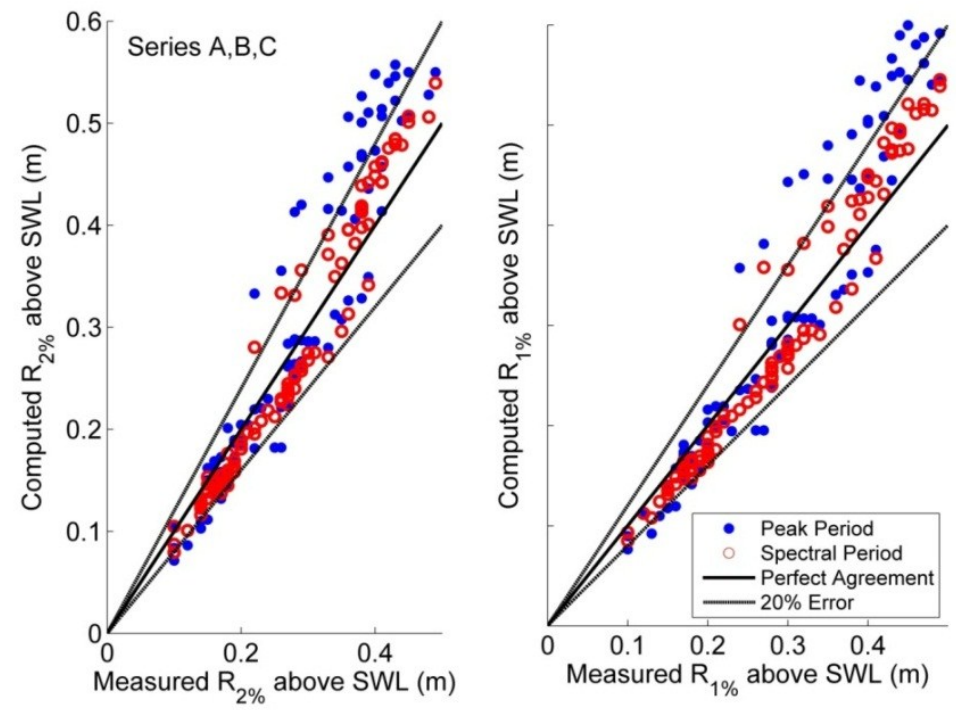

Figure 10: Computed vs. measured $\boldsymbol{R}_{\mathbf{2}}$ and $\boldsymbol{R}_{\mathbf{1}} \%$

van Gent (2001) developed an empirical formula for $R_{2 \%}$ using the measured values of $H_{m o}$ and $T_{m-1,0}$ at the toe in series $\mathrm{P}, \mathrm{A}, \mathrm{B}$, and C. $T_{m-1,0}$ was shown to be a better representative period than $T_{p}$ for this empirical formula. This is also seen in the computations based on CSHORE. In Figure 5, 9 and 10, the agreement for $T_{m-1,0}$ is slightly better than the agreement of $T_{p}$. The agreement between the computed CSHORE runup and the measured runup is no better than the simple empirical formula by van Gent (2001). For actual applications however, the empirical formula is difficult to apply if the toe of the dike is located well inside the surf zone because spectral wave models such as SWAN (Booij et al. 1999) limited to wind wave frequencies may not predict the wave periods $T_{m-1.0}$ and $T_{p}$ at the toe accurately. CSHORE may be applied if its seaward boundary location is chosen to be within the zone where the existing wind wave models can predict $H_{m o}, T_{m-1,0}$, and $T_{p}$ accurately. This practical approach avoids the prediction of infragravity waves in the surf zone. As a result, CSHORE may be a good choice for practical applications such as coastal flood risk mapping.

\section{WAVE RUNUP ON GENTLE SLOPES}

In order to further show CSHORE's versatility, the model was compared to several runup experiments on several different gentle slopes. Mase (1989) measured wave runup using a capacitance wire (2.2 mm diameter) 
installed above $1 \mathrm{~cm}$ deep and $3 \mathrm{~cm}$ wide groove. 30 tests were performed on four different slopes, for 120 tests in all. The significant wave height and wavelength in deep water were tabulated for each test. Slope A was $1 / 5$, slope $\mathrm{B}$ was $1 / 10$, slope $\mathrm{C}$ was $1 / 20$, and slope $\mathrm{D}$ was $1 / 30$. The runup wire height was assumed to be the radius of the runup wire and $\delta_{r}=1 \mathrm{~mm}$. The friction factor was calibrated to 0.001 to account for the groove which is thought to reduce the bottom friction. The significant wave period and wave height at $x=0$ were used as input. Table 3 shows these wave conditions at $\mathrm{x}=0$ for uniform slopes $\mathrm{A}(1 / 5), \mathrm{B}(1 / 10), \mathrm{C}(1 / 20)$, and $\mathrm{D}(1 / 30)$. The water depth of at the toe of the slope was $45 \mathrm{~cm}$ or $43 \mathrm{~cm}$ at the seaward boundary, $x=0$. The significant wave period $T_{s}$ at $x=0$ is the representative wave period in this comparison. The shoaled significant wave height is assumed to be the same as the spectral significant wave height $H_{m o}$ at $x=0$. Comparisons between Tables 1,2, and 3 show these tests include smaller periods and heights than van Gent's data.

Table 3 Wave Conditions at $\mathrm{x}=0$ for Four Uniform Slopes

\begin{tabular}{|c|c|c|c|c|c|}
\hline $\begin{array}{c}\text { Slope } \\
\text { name }\end{array}$ & $\begin{array}{c}\text { Uniform } \\
\text { slope }\end{array}$ & $\begin{array}{c}\text { Number } \\
\text { of tests }\end{array}$ & $\begin{array}{c}\text { Depth } \\
\text { (cm) }\end{array}$ & $\begin{array}{c}\text { Ts } \\
\text { (s) }\end{array}$ & $\begin{array}{c}\boldsymbol{H}_{\boldsymbol{m}} \\
\mathbf{( c m})\end{array}$ \\
\hline $\mathrm{A}$ & $1 / 5$ & 30 & 45 & $0.84-2.42$ & $4.0-10.2$ \\
$\mathrm{~B}$ & $1 / 10$ & 30 & 45 & $0.84-2.29$ & $2.9-10.2$ \\
$\mathrm{C}$ & $1 / 20$ & 30 & 45 & $0.83-2.28$ & $2.7-9.3$ \\
$\mathrm{D}$ & $1 / 30$ & 30 & 43 & $0.81-2.29$ & $2.6-9.2$ \\
\hline
\end{tabular}

The computed CSHORE values of $R_{l / 3}$ and $R_{2 \%}$ are compared to the measured values of Mase's (1989) data. The significant runup height defined as the average of $1 / 3$ highest values of $R$. Figure 11 shows the comparison between the computed results and measured data. The errors varied for the four slopes, but were generally within $20 \%$. The steepest slope (slope A) had the highest runups elevations, while the gentlest slope (slope $\mathrm{D}$ ) had the lowest runup elevations. Mase (1989) proposed empirical formulas for $R_{2} \%$ and $R_{1 / 3}$ using his data. The agreement is slightly better for his formulas which are limited to uniform slopes. As shown with the comparison to van Gent's data, CSHORE is versatile enough to predict wave runup on the slope of an arbitrary geometry.
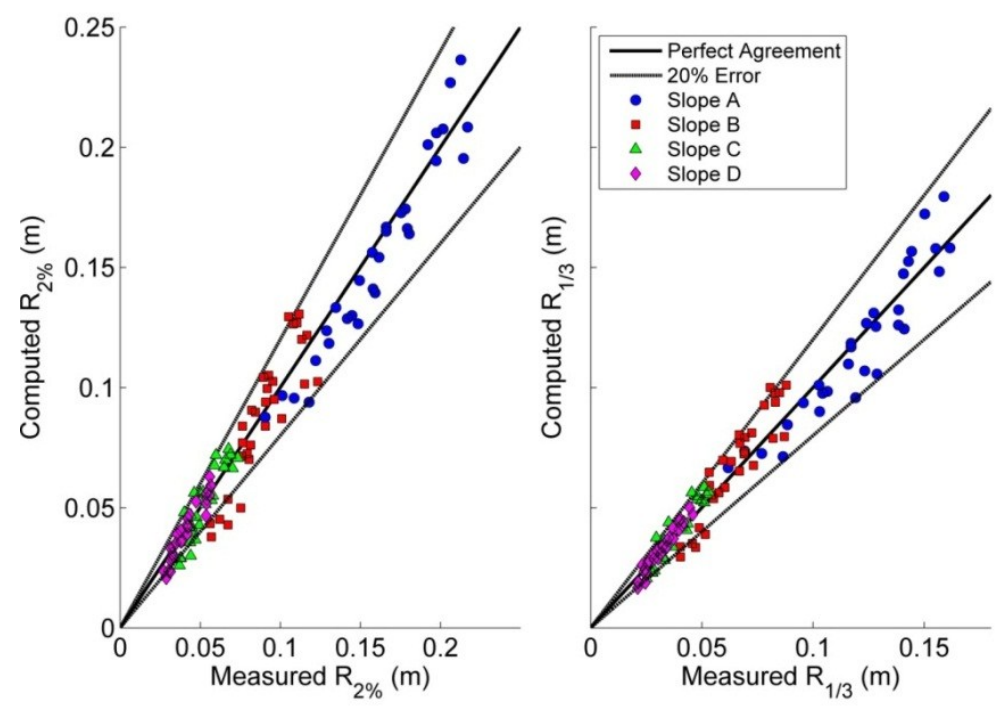

Figure 11: Computed vs. measured $\boldsymbol{R}_{1 / 3}$ and $\boldsymbol{R}_{2} \%$ 


\section{CONCLUSIONS}

CSHORE computation initiated from seaward location $x=0$ where wave setup $=0$. CSHORE predicts the significant wave height transformation from the input wave height at the seaward boundary to the wave height at the toe of the dike. This is an improvement upon runup computation in comparison to empirical formulas based on wave conditions at the dike toe which do not account for wave transformation.

The time-averaged probabilistic model, CSHORE, has been extended to predict irregular wave runup in the wet-dry zone. CSHORE is shown to be robust and computationally efficient when used for predicting wave runup. In addition, beach and dune erosion during a storm can be severe. For coastal flood mapping erosion needs to be considered as runup is dependent on the foreshore and dune profile. CSHORE is a good practical choice since it can predict profile evolution during a storm within a factor of about 2 (Kobayash et al 2010; Figlus et al. 2011).

The calibrated CSHORE is shown to have good agreement when compared with measured results of extreme runup. $2 \%$ and $1 \%$ exceedence runups are predicted within errors of $20 \%$ using $T_{m-1,0}$ at $x=0$ as input on impermeable dikes. After calibrating bottom friction factor to account for laboratory setup, CSHORE is capable of predicting runup on the 120 gentle slope tests by Mase (1989). CSHORE is shown to be able to predict runup for a variety of different geometries. 


\section{REFERENCES}

Booij, N., Ris, R.C., and Holthuijsen, L.H. (1999). "A third-generation wave model for coastal regions. 1. Model description and validation.” J. Geophys. Res., 104(C4), 7649-7666.

Crowell, M., Coulton, K., Johnson, C., Westcott, J., Bellomo, D., Edelman, S., and Hirsch, E. (2010). “An estimate of the U.S. population living in 100-year coastal flood hazard area.” J. Coastal Res., 26(2), 201-211.

EurOtop Manual. (2007). Wave overtopping of sea defenses and related structures:Assessment Manual. http://www.overtopping-manual.com.

Figlus, J., Kobayashi, N., Gralher, C., and Iranzo, V. (2011). "Wave overtopping and overwash of dunes.” J. Waterway, Port, Coastal, Ocean Eng., 137(1), 26-33.

Klopman, G., and van der Meer, J.W. (1999). "Random wave measurements in front of reflective structures.” J. Waterway, Port, Coastal, Ocean Eng., 125(1), 39-45.

Kobayashi, N., de los Santos, F.J., and Kearney, P.G. (2008). "Time-averaged probabilistic model for irregular wave runup on permeable slopes.” J. Waterway, Port, Coastal, Ocean Eng., 134(2), 88-96.

Kobayashi, N., Farhadzadeh, A., and Melby, J.A. (2010). "Wave overtopping and damage progression of stone armor layer." J. Waterway, Port, Coastal, Ocean Eng., 136(5), 257-265.

Mase, H. (1989). "Random wave runup height on gentle slope.” J. Waterway, Port, Coastal, Ocean Eng., 115(5), 649-661.

Nwogu, O., and Demirbilek, Z. (2010). "Infragravity wave motions and runup over shallow fringing reefs." J. Waterway, Port, Coastal, Ocean Eng., 136(6), 295- 305.

Raubenheimer, B. (2002). "Observations and predictions of fluid velocities in the surf and swash zones." J. Geophys. Res., 107(C11), 3190.

Raubenheimer, B., and Guza, R.T. (1996). “Observations and predictions of runup.” J. Geophys. Res., 101(C10), $25,575-25,587$.

Raubenheimer, B., Guza, R.T., and Elgar, S. (2001). "Field observations of wave-driven setdown and setup." J. Geophys. Res., 106(C3), 4629-4638.

Reubenheimer, B., Elgar, S., and Guza, R.T. (2004). "Observations of swash zone velocities: A note on friction coefficients.” J. Geophys. Res., 109, C01027.

van Gent, M.R.A. (1999a). "Physical model investigations on coastal structures with shallow foreshores: 2D model tests on the Petten Sea - defense." MAST-OPTICREST Rep. and Delft Hydr. Rep. H3129, Delft Hydraulics, Delft, The Netherlands.

van Gent, M.R.A. (1999b). "Physical model investigations on coastal structures with shallow foreshores: 2D model tests with single and double-peaked wave energy spectra." Rep.H3608, Delft Hydraulics, Delft, The Netherlands.

van Gent, M.R.A. (2001). "Wave runup on dikes with shallow foreshores." J. Waterway, Port, Coastal, Ocean Eng., 127(5), 254-262. 